\title{
Strengthening Relations with South Korea's Public Diplomacy: Korean Language in India
}

\author{
Nawnit Kumar \\ Ph.D. Candidate, \\ Centre for East Asian Studies, School of International Studies, \\ Jawaharlal Nehru University, New Delhi (India) \\ nawnit.korean@gmail.com
}

\begin{abstract}
Over the last several decades, the role of Public Diplomacy (PD) as an essential part of foreign policy has been continuously gaining popularity on the globe. In 1960, the former US diplomat Edmund Gullion coined the term "Public Diplomacy," and it has been practicing comprehensively in the past few decades. In the world arena, many States are practicing Public Diplomacy and put efforts into their policies and strategies as the means of soft power. The emergence of PD is a current trend in South Korea, and it also can be seen in various sectors or strategies of South Korea. The Korean language is also part of the famous initiative of Korea "Korean Wave" (Hallyu / 한류). In India, South Korea is using Korean language/studies as a tool of PD along with other policies to enhance their culture. In recent years, the worldwide profile of the Korean language has been seen as an especially increment. Thus, this paper aims to emphasise the applicability of the Korean language in the generation of the PD of South Korea. As a tool of Public Diplomacy the uses of Korean Language may show a way to greater regional and even global influence nonetheless. This paper argues not only the current scenario of the Korean language, but it also tries to look at the commencement of it.
\end{abstract}

Keywords: Public Diplomacy, Korean Language, IndiaKorea Relations, Korean Wave, Hallyu in India

\section{INTRODUCTION}

The world is witnessed of the changing characteristics of diplomacy. Many countries are practicing various strategies through different policies on the national and transnational level. In this globalisation Era, Public Diplomacy has gaining attention of the world as a popular form of diplomacy. Over the last several decades, the role of Public Diplomacy as an important part of diplomacy has been continuously gaining popularity on the globe. Public viewpoint and beliefs now straight away deployed an impact on a nation's ability to understand diplomatic gain and diplomacy is no more invisible and oratorical negotiation between the leaders of the nation. Under the changes of diplomatic model, not by confining the public viewpoint but making the best use of their perspective, one nation can influence other nation. In the present, an influence trend of foreign policy is the proactive approach of diplomacy that aims to attain the public interest by endeavouring impact not only on one's people but also on people from other nations. P.D has to turn out as usage of foreign policy among the exchanges global diplomacy paradigms' [1]. In a traditional sense, diplomacy is intergovernmental dialogue, at highest level government officials speaking to each other. On the other hand, public diplomacy centres on the ways one country speaks with the people of another country. In the world arena, many States are practicing Public Diplomacy and put efforts into their policies and strategies as the means of "soft power" diplomacy [2], The "Hard-Power" could not have to win the hearts and minds of people from other countries achieving diplomatic objectives [3].The Public diplomacy means different things to different people. Cull has defined Public diplomacy as an 'International actor's attempt to conduct its foreign policy by engaging with foreign publics. According to Brain Etheridge and Kenneth Osgood, Public diplomacy 'involves the cultivation of public opinion to achieve the desired geopolitical aims of the sponsor' by 'fostering a receptive climate for the sponsor's foreign policies'. As a result of a larger reading public, and the concomitant belief that public opinion could impact upon official relations, it had become increasingly apparent to diplomats and other actors in international relations. In 1960, during a speech the former US diplomat Edmund Gullion coined the term Public Diplomacy. He defined the term as "the means by which government, private groups, and individuals influence the attitudes and opinions of other peoples and governments in such a way as to exercise influence on their foreign policy decisions". Public diplomacy has also become a significant part of countries 'foreign policy and is often used by countries to promote national culture, image and to enhance mutual understanding, cooperation and international partnership. So far the terms 'Cultural diplomacy' and 'Public diplomacy' have been interchangeably [4]. As an enlargement of his theory of soft power (Figure 1), the famous American political scientist Joseph Nye argues for 'smart power'. It is a skilful combination of 'soft power 'and 'hard power'. A nation can proceed with global benefits through soft power strategies and hard power elements by employing smart power.

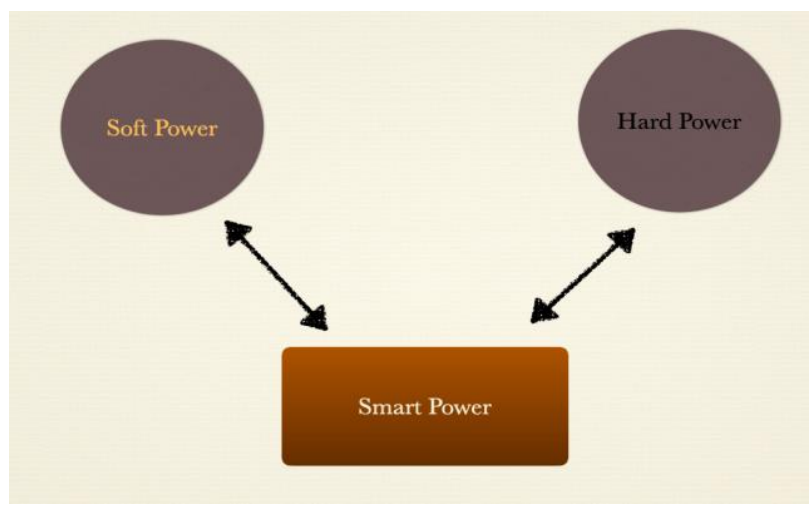

Figure 1: Nye's Smart Power Theor 
He has identified the five critical areas of smart power (Figure: 2). They are technology and innovation; economic integration; public diplomacy; global development; and alliances, partnerships, and institutions. For Nye, in public diplomacy, the aim of communication works not for a government or a nation but direct to their people.

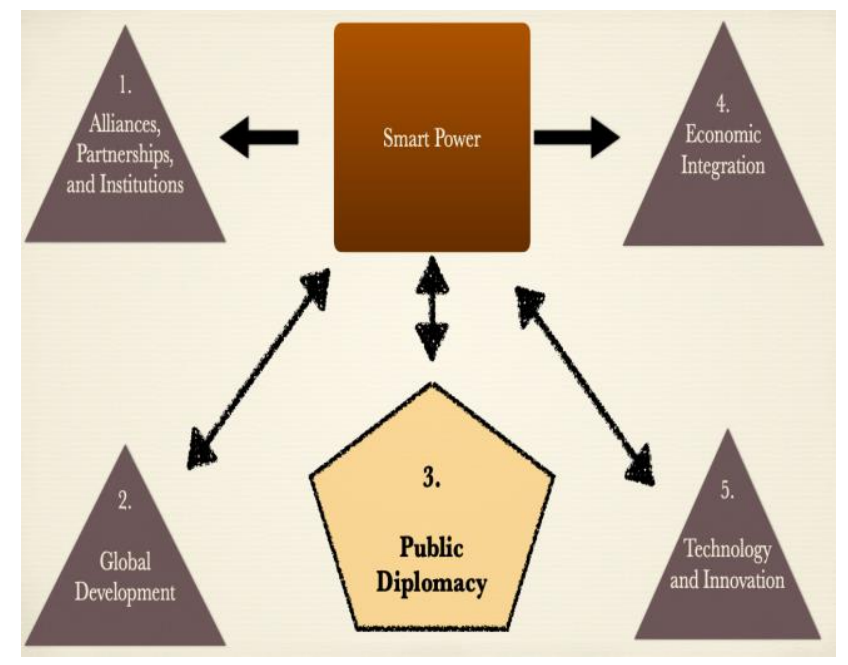

Figure 2: Five critical areas of smart power by Nye

In truth, it is necessary to delineate the two. Cultural diplomacy is a term, also perform in various aspects of public diplomacy. Nicholas Cull (2009), argues "cultural diplomacy is a form of public diplomacy". According to Jessica Gienow-Hecht, meanwhile, cultural between or among people living in two or more different regions'. Cull also states that, meanwhile, that public diplomacy can only be regarded as distinct from informal intercultural relations when it becomes part of an actor's policy. With so many strands to public and cultural diplomacy, it is also helpful to utilise Cull's five-point model (Figure 3) which are Listening (for example: through opinion polling), Advocacy (for example: to build understanding of a policy through the 'dissemination and creation of materials of the information), Cultural Diplomacy (that is to say to promote the interests of the actor as a mechanism the 'dissemination of cultural practices'), Exchange Diplomacy (for example student exchange schemes) and International Broadcasting (for example the "transmission of balanced news over state-funded international radio). These definitions of the constituent parts of public diplomacy. These definitions of the public diplomacy can usefully be applied to the Korean cultural wave or Hallyu as a public diplomacy tool [5].

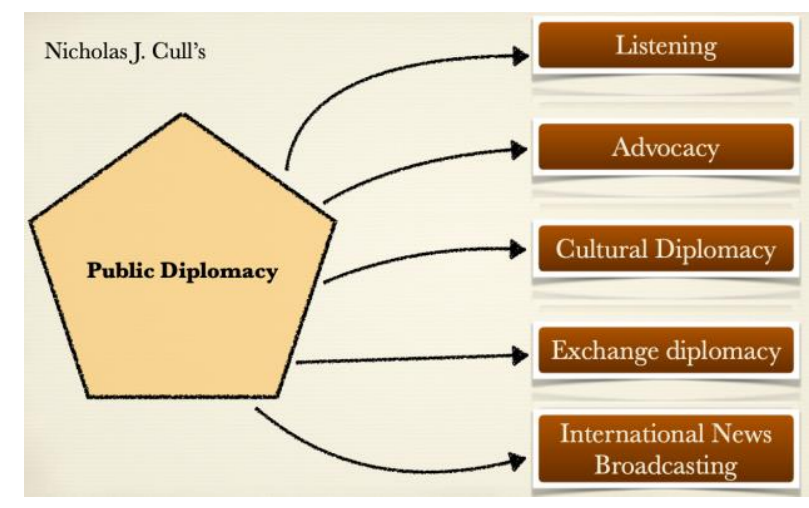

Figure 3: Five point model by Cull
By engaging with foreign people and attempt to conduct its policies, Cll also describes public diplomacy as an 'International Actor.' By means of the five methods described in his model and which he regards as being 'traditionally government to people contact' is also useful to this study. Which he describes as the 'sum total of a nation's contacts with governments and peoples of other nation'. South Korea is a peninsula surrounded by onethird of water and rest by the land. The emergence of public diplomacy is a current trend in South Korea, and it also can be seen in various sectors or policies of South Korea. One of the main contributing factors that made the Korean government realise the need to initiate efforts in improving their foreign policy is the Korean Cultural Wave. In recent years, a powerful "Korean cultural wave" (Hallyu / 한류) is surfing throughout the world, including India. Its popularity is rising with every passing year in India. Korean Cultural Wave ranges from popular music (K-pop), television dramas, cuisine, fashion, movies, dance, martial arts, video games, tourism, and language (Hangul / 한글). Public Diplomacy can be identified with public relations played out on an international stage. Korean cultural wave has exponentially gained traction in not only India, but globally over the past years. It is rapidly growing in popularity. In India, South Korea is practicing Hallyu as a tool of Public diplomacy along with other policies. Since the late 2000 s, most previous studies have emphasised on the modern period of public diplomacy of South Korea, in particular the new foreign policy agenda of the government.

\section{PUBLIC DIPLOMACY OF SOUTH KOREA}

South Korea is a well example of rapid political and socioeconomic development. South Korea once addressed as a "nightmare," a "sick society" and a "bottomless pit" [6] for its poor conditions which, in the words of General Douglas MacArthur, even if a "miracle" happened, would have needed a century "to recover from the Korean War" [7]. As South Korea's economy grows, discussions on the role of public diplomacy among society of states also increase. South Korea has demonstrated dramatic economic growth by adopting a great market policy which has ran for several years, and this trend contributed to the growth of South Korea's socio-political stability and ambition for fulfilling their economy goals. The Invitation of Diplomatic Envoys in the Early 21st Century South Korea practise public diplomacy with different strategy based on their historical and cultural traditions. Korean government's public diplomacy was based on trusted relationship with people. We can call this as people's diplomacy which has its basis on the public. Despite being a relatively new actor in public diplomacy official launched in 2010 [8], South Korea actively works in this field and promotes various aspects of culture, traditions and language worldwide through it. The Western and Asian countries have become important partners for South Korea, as these are biggest trade destinations of South Korea. South Korea in Western and Asian countries is well known for its technological advancement and various Cultural products. The direct communications with foreign nationals, Korean public diplomacy necessitate encouraging diplomatic relations by exchanging history, traditions, culture, arts, values, policies and visions. By achieving the belief of the international community and enlarging country's global influence that magnified diplomatic relations and national image. When the Korean government established the three axes governing diplomatic relations beside state diplomacy and economic diplomacy public diplomacy came into full-fledged as of 2010. The public diplomacy act established in August of 2017, since then Korean government has put all efforts to sustain public diplomacy funds 
and strengthen relations among ministerial sects. The Ministry Of Foreign Affairs (MOFA) of South Korea currently functioning as an essential part for activities and projects for the region-specific public diplomacy in partnership with 184 foreign embassies. It also bears the various type of programs of public diplomacies. Among all projects of MOFA, One of the most popular projects is 'Public Diplomacy Project of Korean Citizens', in this project every people of Korea is given support and opportunity to become a "public diplomacy ambassador."

\section{KOREAN LANGUAGE IN INDIA}

The relations between India and Korea has already developed in the 4th Century. The elements of all cultures can be the same such as accent, language, norms, values and symbols. For access to culture, language can be the first component. It is an "organised, generally, agreed-upon learned symbol system that is used to represent the experiences within a geographic or cultural community" [9]. It is a necessary instrument of communication to express or symbolise ideas and feelings. Pankaj N. Mohan (2017) argues "In the 1990's when Korea established its reputation as an economic powerhouse and India adopted "Look East Policy," a bridge of brisk cultural interaction between the two countries emerged and India started accommodating Hallyu or components of Korean culture in earnest. Establishment of undergraduate and postgraduate programs in Korean language and Korean studies at several universities in India is the first major manifestation of Hallyu." $\mathrm{He}$ tries to show the relations between both countries since ancient time through the story of legend Queen Heo Hwang-ok (Princess Suriratna) to present century [10]. The KCC is playing a significant role in the diplomatic relations between South Korea and India since its establishment in the year 2012. Since then, the $\mathrm{KCC}$ has become an essential factor in the way to promote Korean language and culture in India. Here, the culture industry takes the form of public relations, "the manufacturing of goodwill per se, without regard for particular firms or saleable objects" [11]. The KCC is partnering with the various institutions to promote and popularise Korean language learning in India. Due to the job prospects, the teaching-learning of Hangul or Korean language in India has become popular that South Korean conglomerate offers to the speakers of Korean. The embassy of South Korea in the capital of India (New Delhi) performs a significant role in promoting students to learn the Korean language in various Indian universities. The measures taken extend to the ambassador of South Korea and other staff members who are related to the diplomacy activities. In 2016, to promote the Korean language learning programme, they also use to visit several Indian institutes and universities, such as Jawaharlal Nehru University, University of Delhi, Manipur Central University, Indira Gandhi National Open University, Jamia Millia Islamia, Guwahati University and Sikkim Manipal University. They also work in the field of increasing academic exchange programme between the two countries. Korean Cultural Centre and The Embassy of Korea actively organises various programs like speech contests, essay writing competitions, quiz competitions-pop contests, dance competitions video competitions for college, universities and school students and organising different contexts and seminars on themes associated to Korean culture. A new form of martial arts 'Taekwondo' (태권도), which is also a traditional martial art of Korea has gained popularity on the globe. And as a skill for self-defence, it has also been gaining popularity in the many parts of India. In this regard, to encourage the popularity of Taekwondo, the Korean Cultural Centre has been organising many events and use to conduct classes in India. All these measures points to the structuralist paradigm of popular culture, where it becomes the ideological machine that effortlessly reproduces the existing structures of power, placing us in specific reading positions. Korean studies in India commenced in 1976 at Jawaharlal Nehru University (JNU) when it was able to attract Professor Suh Kyung Soo from Dongguk University in Seoul and a full-time pre-degree diploma course in the Korean language was established [11]. Prof. Suh was succeeded by Professors Oh Guk Keun, Chung Pyung Jo, Lee Pyong Rae and others who continued the program with the help of Professor R. R. Krishnan who taught Korean history and politics at the university. In 1995 Jawaharlal Nehru University opened a three-year undergraduate degree program in Korean, and in subsequent years it was further systematised and MA, M-Phil and $\mathrm{PhD}$ programs in Korean language and literature were added. Delhi University was the second university in India to open courses in Korean language. Currently Central University of Jharkhand (Ranchi), Manipur University, English and Foreign Languages University (Hyderabad), Korean Cultural Centre (Delhi), Sejong Centre (Patna), and Nalanda University offer courses in Korean language. Inko Center at Chennai, established by Hyundai has also been spreading the knowledge of Korean culture through lectures and culture programs. The current government of India is also doing great jobs through their New Education Policy-2020 (NEP-2020). Through this NEP, the government of India has adopted the Korean Language as a course which will also be offered at Secondary level. This will allow "students to learn about the cultures of the world and to enrich their global knowledge and mobility according to their own interests and aspirations," NEP 2020 [12].

\section{CONCLUSION}

In India, South Korea is spreading its public diplomacy through mainly three pillars:- Cultural Diplomacy, Knowledge based Diplomacy and Policy Advocacy. Public Diplomacy really can play an important role in creating friendly identities between two countries. The core of public diplomacy is "to wins Hearts and Minds of people." South Korea has a very dynamic and diverse culture contents. In this Era the Hallyu now expand beyond those K-Pop and K-Drama and include K-food, K-beauty, K-games, K-tourism Korean Language etc. Due to the job prospects, the learning of Hangul or Korean language in India has become popular that South Korean conglomerate offers to the speakers of Korean. It is apparent that, Korean Studies program and Korearelated departments in India contribute specialist knowledge on Korean language and culture and seek to foster scholarship on pre- modern Korea, the complexities of Korea's colonial and postcolonial history, and the rapidity of changes in Korean society. Indian universities have a few qualified scholars who are experts on Korea in the areas of Korean linguistics, literature, language education, and history and politics. Collectively, the group represents an important channel of Korea's soft power. The growing craze of K-pop, k-dramas, people looking for job opportunities, exploring foreign language, visiting Korea has led many Indians to engage with Korean language Institutions such as Korean Culture Centre India (KCCI), Indira Gandhi National Open University (IGNOU), Jawaharlal Nehru University (JNU), University of Delhi (DU), Jamia Millia Islamia (JMI) etc. 


\section{REFERENCES}

[1] Leonard, M. (2002). Diplomacy by Other Means: Foreign Policy.

[2] Nye Jr, J. S. (2008). Public diplomacy and soft power. The annals of the American academy of political and social science, 616(1), 94-109.

[3] Bátora, J. (2005). Public diplomacy in small and mediumsized states: Norway and Canada. The Hague: Netherlands Institute of International Relations.

[4] Cull, N. J. (2008). Public diplomacy before Gullion: The evolution of a phrase. In Routledge handbook of public diplomacy (pp. 39-43). Routledge.

[5] Cull, N. J. (2009). Public diplomacy: Lessons from the past (No. s 12). Los Angeles, CA: Figueroa Press.

[6] Sung, J. K. (2010). Was There an Economic Miracle in Korea. Development Experience of the Korean Economy, 11-20.

[7] KOICA (Korea International Cooperation Agency). 2011. 1991-2010: 20 Years of KOICA. Seongnam: KOICA.

[8] Ma, Young Sam, Song Jung-he, and Dewey Moore. 2012. "Korea's Public Diplomacy: A New Initiative for the Future.” Asan Institute for Policy Studies 39 (December).

[9] Samovar, L. A., Porter, R. E., McDaniel, E. R., \& Roy, C. S. (2014). Intercultural communication: A reader. Cengage learning.

[10] Mohan, P. N. (2017), Hallyu in India: A Study of the Reception of Korean Culture in India Today. Journal of Contemporary Korean Studies, 4(1), 123-137.

[11] Adorno, T. W., \& Rabinbach, A. G. (1975). Culture industry reconsidered. New German Critique, (6), 12-19.

[12] Sibal, S. 2020. [Online]. [Accessed 9 September 2020]. Available from: https://www.dnaindia.com/india/reportenvoys-welcome-inclusion-of-foreign-languages-in-neweducation-policy-2835789

[13] Korea Tourism Organization. Brief History of KTO Retrieved November 11, 2018 from http://kto.visitkorea.or.kr/enu/ek/ek_1_1_3_1.jsp

[14] Dhawan, R. K. (2017), Korea's Cultural Diplomacy: An Analysis of the Hallyu in Diplomacy," The Western Political Quarterly : 279-295. 